\title{
Fundamental piezoresistive coefficients of p-type single crystalline 3C-SiC
}

Hoang-Phuong Phan, ${ }^{1, a)}$ Dzung Viet Dao, ${ }^{1,2}$ Philip Tanner, ${ }^{1}$ Li Wang, ${ }^{1}$ Nam-Trung Nguyen, ${ }^{1}$

Yong Zhu, ${ }^{1,2}$ and Sima Dimitrijev ${ }^{1,2}$

1) Queensland Micro- and Nanotechnology Centre, Griffith University, Queensland,

Australia

${ }^{2)}$ School of Engineering, Griffith University, Queensland, Australia

(Dated: 28 February 2014)

The orientation dependence of the piezoresistive effect of p-type single crystalline 3C-SiC thin film grown on a (100)Si wafer was characterized. The longitudinal, transverse gauge factors in [100] orientation, and longitudinal gauge factor in [110] orientation were found to be 5.8, -5.2 and 30.3, respectively. The fundamental piezoresistive coeffictients $\pi_{11}, \pi_{12}$ and $\pi_{44}$ of p-type $3 \mathrm{C}-\mathrm{SiC}$ were obtained to be $1.5 \times 10^{-11} \mathrm{~Pa}^{-1}$, $-1.4 \times 10^{-11} \mathrm{~Pa}^{-1}$ and $18.1 \times 10^{-11} \mathrm{~Pa}^{-1}$, respectively. From these coefficients, the piezoresistive effect in any crystallographic orientation in p-type single crystalline $3 \mathrm{C}-\mathrm{SiC}$ can be estimated, which is very valuable in designing micro-mechanical sensors.

Silicon carbide $(\mathrm{SiC})$ is a promising material for MEMS (Micro Electro Mechanical Systems) transducers used in harsh environments, due to its high energy band gap, chemical inertness and high stiffness ${ }^{1}$. Among many poly types, the cubic crystal silicon carbide (3C-SiC) is considered to be the most suitable polytype for MEMS applications, since it can be grown directly on a Si substrate and the electrical insulation between 3C-SiC layer and $\mathrm{Si}$ substrate is achieved by the $\mathrm{SiC} / \mathrm{Si}$ heterojunction ${ }^{2}$.

One of the most common methods for mechanical sensing is based on the piezoresistive effect which has been intensively studied in $\mathrm{Si}$ so $\mathrm{far}^{3-5}$. Research on the piezoresistive effect of $3 \mathrm{C}-\mathrm{SiC}$ recently attracted significant attention for applications used in high temperature environments ${ }^{6-10}$. Large piezoresistive effects in $\mathrm{n}$ type single crystalline $3 \mathrm{C}-\mathrm{SiC}$ with the longitudinal gauge factors (GF) as large as -31.8 in [100] orientation have been reported ${ }^{9,10}$. Various piezoresistive pressure sensors based on n-type 3C-SiC with the large range of operating temperature up to $500{ }^{\circ} \mathrm{C}$ have been developed, demonstrating the high potential of $3 \mathrm{C}-\mathrm{SiC}$ material in MEMS sensing devices ${ }^{11-13}$. Most previous studies presented the piezoresistive effect in n-type $3 \mathrm{C}-\mathrm{SiC}$, with very limited results being available for $\mathrm{p}$-type $3 \mathrm{C}-\mathrm{SiC}^{14}$. One considerable reason for the limited work on p-type $3 \mathrm{C}-\mathrm{SiC}$ is due to the high growth temperature at around $1350{ }^{\circ} \mathrm{C}$ which causes the redistribution of the dopant in $\mathrm{Si}$ and the accumulation of the thermal mismatch between $\mathrm{SiC}$ and $\mathrm{Si}^{18}$. In a previous study ${ }^{2}$, we have characterized the piezoresistive effect in [110] orientation of p-type single crystalline 3C-SiC thin film grown on a Si substrate by LPCVD (Low Pressure Chemical Vapour Deposition) at low temperature of $1000{ }^{\circ} \mathrm{C}$ with large GF of 30.3.

Understanding of the piezoresistive effect in arbitrary crystallographic orientations plays an important role in designing highly sensivite p-type single crystalline 3C$\mathrm{SiC}$ based mechanical sensors. Therefore, the aim of this paper is to determine the fundamental piezoresistive co-

\footnotetext{
a)Electronic mail: hoangphuong.phan@griffithuni.edu.au
}
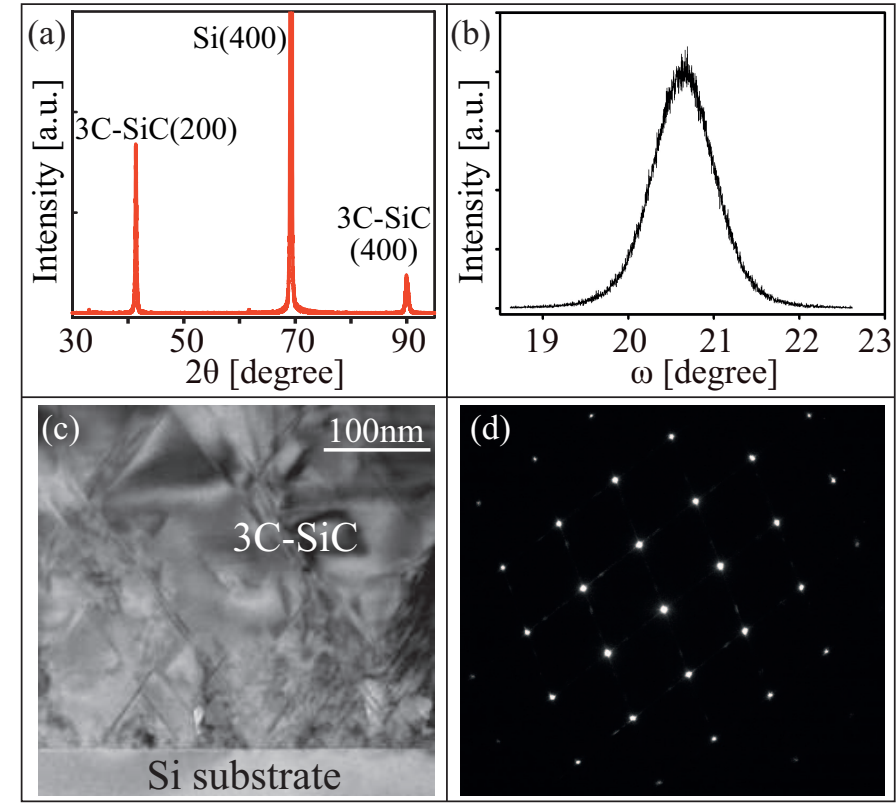

FIG. 1. (a) The XRD graph of 3C-SiC grown on (100)Si; (b)The rocking curve scan of 3C-SiC; (c) The TEM image of 3C-SiC; (d) The SAED image of 3C-SiC.

efficients, and to investigate the orientation dependence of the piezoresistive effect in p-type single crystalline 3C$\mathrm{SiC}$.

The p-type single crystalline $3 \mathrm{C}-\mathrm{SiC}$ with the thickness of $280 \mathrm{~nm}$ was epitaxially grown on p-type (100) $\mathrm{Si}$, and in-situ doped with aluminum by using PPCVD $^{19}$. The full-range $2 \theta-\omega$ of the X-Ray Diffraction (XRD) measurement indicated that single crystalline (100)3C-SiC was grown on Si substrate (Fig. 1(a)). The full width at half maximum (FWHM) of $\mathrm{SiC}(200)$ peak in the $2 \theta-\omega$ scan is $0.26^{\circ}$. The FWHM of rocking curve scan of the $\mathrm{SiC}(200)$ peak is $0.80^{\circ}$ as shown in Fig. 1(b). The transmission electron microscopy (TEM) image in Fig. 1(c) shows that there are no boundaries in the single crystalline 3C-SiC and the only defects are staking faults. The selected area electron diffraction (SAED) displayed 

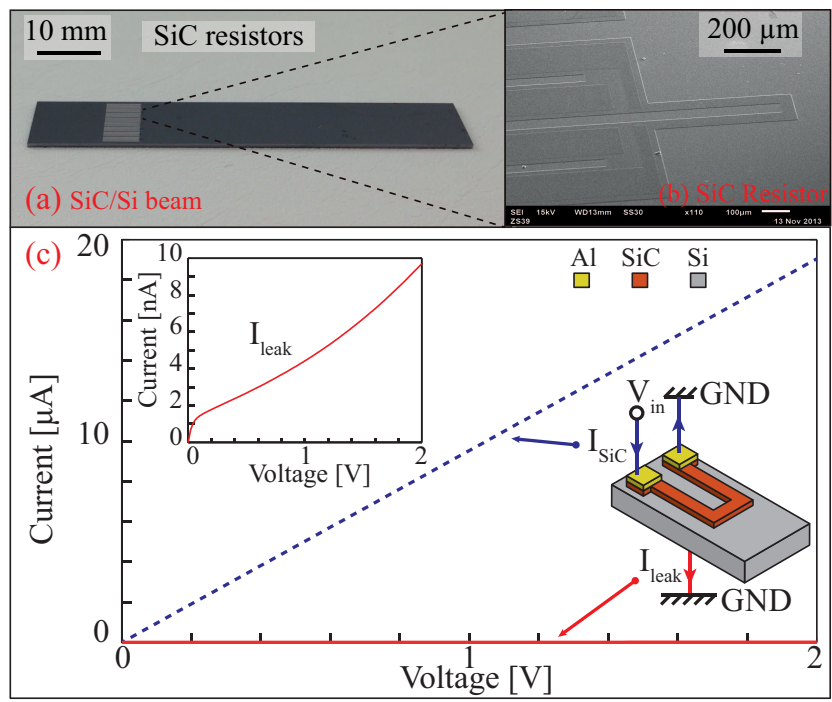

FIG. 2. (a) Photograph of the SiC/Si beam; (b) Scanning electron microscopy (SEM) image of a $\mathrm{SiC}$ resistor; (c) IV curve of $\mathrm{SiC}$ resistor (small graph: zoom-in of the current leakage through $\mathrm{SiC} / \mathrm{Si}$ junction).

in Fig. 1(d) confirms that the grown 3C-SiC is single crystalline. The Hall-effect measurement was performed to characterize the electrical properties of the grown $\mathrm{SiC}$ film. The resistivity of the $\mathrm{SiC}$ film was measured to be $0.14 \Omega \mathrm{cm}$ and the hole mobility of the single crystalline $3 \mathrm{C}-\mathrm{SiC}$ film was found to be $9 \mathrm{~cm}^{2} / \mathrm{Vs}$ which is a reasonable value for the doping level of $5 \times 10^{18} \mathrm{~cm}^{-3}$, indicating the good crystal quality. SiC piezoresistor on Si substrate was patterned by a conventional photolithography process and then diced into a strip $60 \mathrm{~mm} \times 9 \mathrm{~mm} \times 0.625$ $\mathrm{mm}$ (Fig. 2(a)). SEM photograph of a $\mathrm{SiC}$ resistor is shown in Fig. 2(b). The carrier concentration of the p-type single crystalline $\mathrm{SiC}$ in this research was $5 \times 10^{18}$ $\mathrm{cm}^{-3}$, while the carrier concentration of the Si substrate

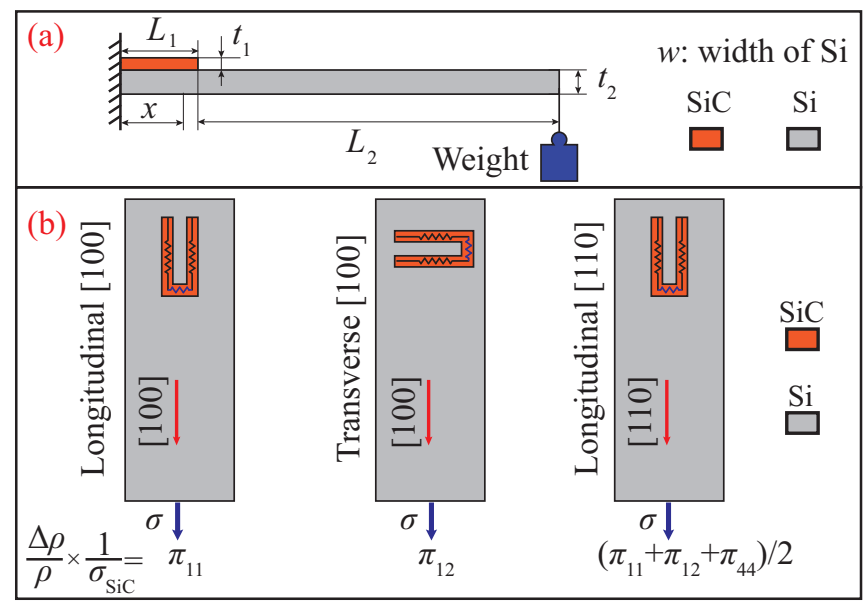

FIG. 3. Schematic diagram showing the bending experiment for measuring the gauge factors: (a) side view; (b) top view of cantilever. was $5 \times 10^{14} \mathrm{~cm}^{-3}$. The issue of current leakage through $\mathrm{SiC}$ and $\mathrm{Si}$ junction was investigated to make sure that $\mathrm{Si}$ would not affect the measured gauge factor of SiC. The current leakage through $\mathrm{SiC} / \mathrm{Si}$ heterojunction at the applied voltage of $0.5 \mathrm{~V}$ was found to be about $0.05 \%$ of the current flowing through $\mathrm{SiC}$ resistor as shown in Fig. 2(c). This result indicates that Si substrate will not contribute to the measurement of the $\mathrm{GF}$ of the $\mathrm{SiC}$ thin film.

The GF is measured by the bending beam method, and the four point measurement was employed to determine the resistance change of the p-type 3C-SiC (Fig. 3). GFs of the $\mathrm{SiC}$ resistors were obtained from the relative resistance change and the strain: $G F=(\Delta R / R) / \varepsilon_{\mathrm{SiC}}$. In order to calculate the strain $\varepsilon_{\mathrm{SiC}}$ of the $\mathrm{SiC}$ layer, bending model of a bilayered beam was taken into account as the $\mathrm{SiC}$ was epitaxially grown on $\mathrm{Si}$ substrate. The lateral strain of $\mathrm{SiC}$ resistance is ${ }^{20}$ :

$$
\varepsilon_{\mathrm{SiC}}(x)=-\frac{F}{w D_{1}}\left(L_{1}+L_{2}-x\right) t_{n}
$$

where $F$ is the applied force; $t_{n}$ is the distance from neutral axis to the $\mathrm{SiC}$ layer; and paremeters $w, L_{1}, L_{2}$ are dimensions as described in Fig. 3a. The bending modulus per unit width $D_{1}$ is deduced from ${ }^{21}$ :

$$
D_{1}=\frac{E_{1}^{2} t_{1}^{4}+E_{2}^{2} t_{2}^{4}+2 E_{1} E_{2} t_{1} t_{2}\left(2 t_{2}^{2}+2 t_{1}^{2}+3 t_{1} t_{2}\right)}{12\left(E_{1} t_{1}+E_{2} t_{2}\right)}
$$

where $E_{1}$ is the Young's modulus of $\mathrm{SiC}(330 \mathrm{GPa})^{22}$, and $E_{2}$ is the Young's modulus of $\mathrm{Si}$ (130 GPa in [100] orientation and $169 \mathrm{GPa}$ in [110] orientation). As the thickness of $\mathrm{SiC}$ in our design is only $0.05 \%$ of the $\mathrm{Si}$ layer, the strain calculated from Eq. 1 is approximately the same as that of the upper surface of the Si substrate ${ }^{2}$. Finite Element Method (FEM) was carried out, using COMSOL multiphysics to estimate the strain of the beam.

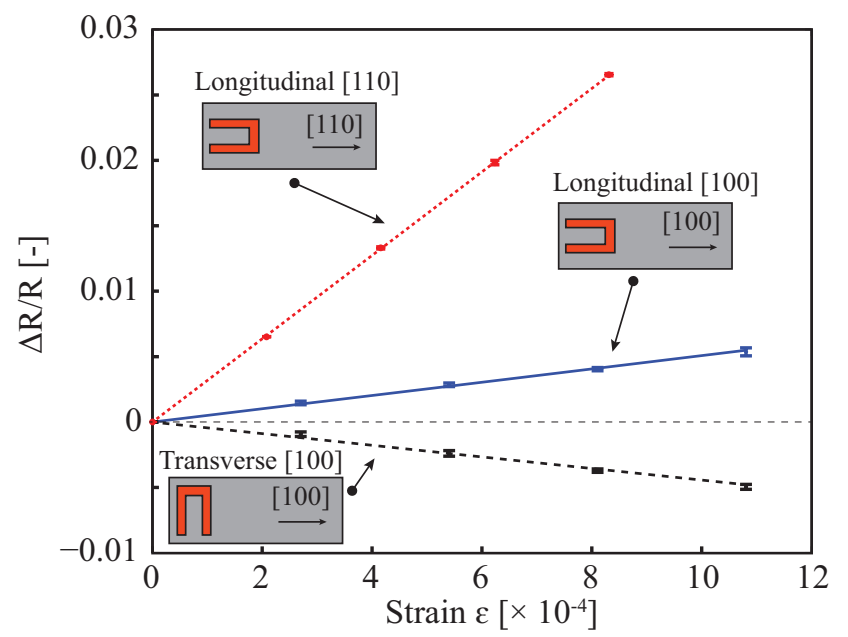

FIG. 4. Relationship between relative resistance change of $\mathrm{SiC}$ resistors alligned in different orientations and applied strains. 
TABLE I. List of GF of single crystalline $\mathrm{SiC}$ in this work and the literature. (* indicated the result in this study)

\begin{tabular}{cccccc}
\hline \hline Polytype & $\begin{array}{c}\text { Growing } \\
\text { process }\end{array}$ & Type & $\begin{array}{c}\text { Carriers } \\
\text { concentration }\end{array}$ & $\begin{array}{c}\text { Thickness } \\
\text { of } \mathrm{SiC}[\mu \mathrm{m}]\end{array}$ & $\mathrm{GF}$ \\
\hline $3 \mathrm{C}-\mathrm{SiC}^{*}$ & LPCVD & $\mathrm{p}$ & $5 \times 10^{18}$ & 0.28 & 30.3 \\
$3 \mathrm{C}-\mathrm{SiC}^{10}$ & APCVD & $\mathrm{n}$ & $\sim 10^{18}$ & 10 & -31.8 \\
$3 \mathrm{C}-\mathrm{SiC}^{9}$ & HMCVD & $\mathrm{n}$ & $\sim 10^{18}$ & 2 & -27 \\
$3 \mathrm{C}-\mathrm{SiC}^{13}$ & APCVD & $\mathrm{n}$ & unintentional & 0.5 & -18.8 \\
$3 \mathrm{C}-\mathrm{SiC}^{7}$ & LPCVD & $\mathrm{n}$ & $0.4 \sim 2 \times 10^{17}$ & 2.3 & -24.8 \\
& & & & 0.2 & 3 \\
$4 \mathrm{H}-\mathrm{SiC}^{15}$ & - & $\mathrm{n}$ & $1.5 \times 10^{19}$ & 1 & 20.8 \\
$6 \mathrm{H}-\mathrm{SiC}^{16}$ & - & $\mathrm{n}$ & $3.8 \times 10^{18}$ & 2 & -29.4 \\
$6 \mathrm{H}-\mathrm{SiC}^{17}$ & - & $\mathrm{p}$ & $2 \times 10^{19}$ & 2 & 27 \\
\hline \hline
\end{tabular}

The simulation result was in agreement with the theoretically calculated value discussed above. Accordingly, the strains of the $\mathrm{SiC}$ resistors were in the ranges of $0 \sim 820$ ppm and 0 1100 ppm for resistors aligned in [110] orientation and [100] orientation, respectively. From the possible errors of the $\mathrm{SiC} / \mathrm{Si}$ beam dimensions and the misalignment of $\mathrm{SiC}$ resistor on $\mathrm{Si}$ beam occurred during fabrication process ${ }^{23}$, we estimated the error of the strain obtained from the simulation is about 5\%. Figure 4 shows the relationship between relative resistance change and applied strain, which reveals that $\mathrm{SiC}$ resistor in [110] direction is more sensitive than that aligned in [100] orientation. The longitudinal GFs in [100] and [110] orientation have a positive value of +5.0 and +30.3 , respectively, while the transverse GF in [100] orientation has a negative value of -4.6 .

Table I shows the comparison between the GF of ptype 3C-SiC presented in this work with the GFs of other polytypes reported in the literature. The GF of n-type $3 \mathrm{C}-\mathrm{SiC}$ varies with the growth conditions, the thickness of the $\mathrm{SiC}$ and the doping level. The results found in this study is quite impressive as the GF of p-type single crystalline $3 \mathrm{C}-\mathrm{SiC}$ thin film $(280 \mathrm{~nm})$ is comparable with previous research in n-type 3C-SiC with larger thicknesses.

The GFs measured above were used to calculate the fundamental piezoresistive coefficients. The change of the resistivity of $\mathrm{SiC}$ is ${ }^{24}$ :

$$
\Delta \rho / \rho=G F \times \varepsilon=\pi_{l} \sigma_{l}+\pi_{t} \sigma_{t}+\pi_{s} \sigma_{s}
$$

where $\sigma_{l}, \sigma_{t}, \sigma_{s}$ are longitudinal, transverse and shear stresses, respectively, and $\pi_{l}, \pi_{t}, \pi_{s}$ are longitudinal, transverse and shear piezoresistive coefficients, respectively. Let $\theta$ be the angle between longitudinal axis of the $\mathrm{SiC}$ resistor and [100] orietation in (100) plane. $\pi_{l}, \pi_{t}, \pi_{s}$ are deduced from the fundamental piezoresistive coefficients as ${ }^{24}$ :

$$
\left\{\begin{array}{l}
\pi_{l}=\pi_{11}-\frac{1}{2}\left(\pi_{11}-\pi_{12}-\pi_{44}\right) \sin ^{2} 2 \theta \\
\pi_{t}=\pi_{12}+\frac{1}{2}\left(\pi_{11}-\pi_{12}-\pi_{44}\right) \sin ^{2} 2 \theta \\
\pi_{s}=-\frac{1}{2}\left(\pi_{11}-\pi_{12}-\pi_{44}\right) \sin 4 \theta
\end{array}\right.
$$

From Eq. 3 and Eq. 4, and the GFs measured in [100] $\left(\theta=0^{\circ}\right)$ and $[110]\left(\theta=45^{\circ}\right)$ orientations, the fundamental piezoresistive coefficient in the principal coordinate $\pi_{11}, \pi_{12}$ and $\pi_{44}$ were found to be $1.5 \times 10^{-11} \mathrm{~Pa}^{-1}$, $-1.4 \times 10^{-11} \mathrm{~Pa}^{-1}, 18.1 \times 10^{-11} \mathrm{~Pa}^{-1}$, respectively. This result indicates that the piezoresistive effect in p-type single crystalline $3 \mathrm{C}-\mathrm{SiC}$ has the same characteristic as p-type single crystalline $\mathrm{Si}$, i.e. the shear piezoresistive coefficient $\left(\pi_{44}\right)$ is much larger than normal piezoresistive coefficients $\left(\pi_{11}\right.$ and $\left.\pi_{12}\right)$. As 3C-SiC has the cubic crystal structure like $\mathrm{Si}$, the model of effect of strain and symmetry in cubic semiconductor proposed by Bir and Pikus ${ }^{25}$ can be used to explain the piezoresistive effect in single crystalline $3 \mathrm{C}-\mathrm{SiC}$. The piezoresistive coefficients $\pi_{11}, \pi_{12}$ are corresponding to the uniaxial stresses applied in [100] direction in which the band warping is negligible, and the dominant mechanism of the piezoresistance is the change of scattering rate which is relatively small. The piezoresistive coefficients $\pi_{44}$ on the other hand, is corresponding to the uniaxial stress in [110] orientation, where the energy surface is significantly warped, leading to the change of the effective mass and hole occupation in the heavy hole and light hole bands. Therefore, the uniaxial stress in [110] orientation is considered to bring more significant piezoresistive effect than the uniaxial stress in [100] orientation.

Based on the fundamental piezoresistive coefficients, the piezoresistive effect in an arbitrary crystallographic orientation can be estimated, which plays an important role in designing the sensitivity of p-type single crystalline 3C-SiC based mechanical sensors. The longitudinal, transverse and shear piezoresistive coeffi-

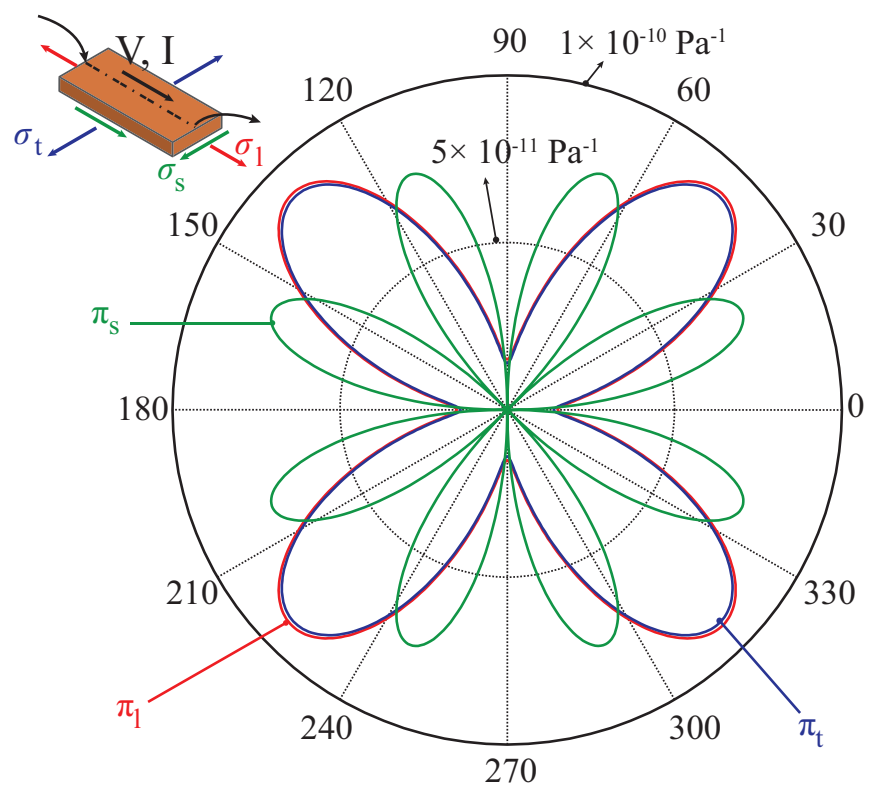

FIG. 5. Piezoresistive coefficients $\pi_{l}, \pi_{t}, \pi_{s}$ in (100) plane of ptype single crystalline $3 \mathrm{C}$-SiC (In some literature ${ }^{24}, \pi_{l}, \pi_{t}, \pi_{s}$ are denoted as $\pi_{11}^{\prime}, \pi_{12}^{\prime}$ and $\left.\pi_{16}^{\prime}\right)$. 
cients of an arbitrary orientation in (100) $\mathrm{SiC}$ plane is graphically presented in Fig. 5. It can be seen that in [110] orientation, the transverse and longitudinal coefficients reach maximum values.

In conclusion, the fundamental piezoresistive coefficients of p-type single crystalline $3 \mathrm{C}$-SiC were obtained. The gauge factor of p-type $3 \mathrm{C}-\mathrm{SiC}$ resistor is significantly dominated by the shear piezoresistive coefficient $\pi_{44}$. Compared to p-type single crystalline silicon ${ }^{24}$ $\left(\pi_{44}=115 \times 10^{-11} \mathrm{~Pa}^{-1}\right.$ at the doping concentration of $5 \times 10^{18} \mathrm{~cm}^{-3}$ ), the shear piezoresistive coefficient of p-type single crystalline $\mathrm{SiC}$ is relatively small. However with the advantages of $3 \mathrm{C}-\mathrm{SiC}$ such as wide bandgap, high melting point, high $\mathrm{Q}$ factor and excellent chemical inertness, the piezoresistive effect in p-type single crystalline $3 \mathrm{C}-\mathrm{SiC}$ is a potential candidate for harsh environment and high frequency applications. From graphical study on the dependence of the piezoresistive coefficients on orientation, we suggest that when designing p-type 3C-SiC based mechanical sensors in the (100) plane, the [110] orientation should be selected to achieve maximum sensitivity.

The authors would like to thank Dr. Jisheng Han, Lin Zhang at Queensland Micro- and Nanotechnology Centre and Harrison Brooke at Griffith University for the preparation of the samples. This work was performed in part at the Queensland node of the Australian National Fabrication Facility, a company established under the National Collaborative Research Infrastructure Strategy to provide nano and micro-fabrication facilities for Australia's researchers. This work has been partially supported by the Griffith University's New Researcher Grants.

\footnotetext{
${ }^{1}$ M. Mehregany, C. A. Zorman, N. Rajan, and C. H. Wu, Proc. IEEE 86(8), 1594 (1998).

${ }^{2}$ H. P. Phan, P. Tanner, D. V. Dao, L. Wang, N. T. Nguyen, Y. Zhu, and S. Dimitrijev, IEEE Electron Device Lett. 35(3), 399-401 (2014).
}

${ }^{3}$ D. V. Dao, T. Toriyama, J. Wells, and S. Sugiyama, Sensors and Materials 15(3), 113 (2003).

${ }^{4}$ D. V. Dao, T. Toriyama, and S. Sugiyama, Proc. IEEE Sensors 2004, Vienna, Austria, 1464 (2004).

${ }^{5}$ D. V. Dao, K. Nakamura, T. T Bui, and S. Sugiyama, Adv. Nat. Sci: Nanosci. Nanotechnol. 1(1), 013001 (2010).

${ }^{6} \mathrm{~J} . \mathrm{Bi}, \mathrm{G}$. Wei, L. Wang, F. Gao, J. Zheng, B. Tang, and W. Yang, J. Mater. Chem. C. 1, 4514 (2013).

${ }^{7}$ M. Eickoff, M. Moller, G. Kroetz, and M. Stutzmann, J. Appl. Phys. 96, 2872 (2004).

${ }^{8}$ T. Toriyama and S. Sugiyama, Appl. Phys. Lett. 81, 2797 (2002).

${ }^{9}$ K. Yasui, H. Miura, M. Takata, and T. Akahane, Thin Solid Films 516, 644 (2008).

${ }^{10}$ S. J. Shor, D. Goldstein, and A. D. Kurtz, IEEE Trans. Electron Devices. 40(6), 1093 (1993).

${ }^{11}$ R. Ziermann, J. von Berg, E. Obermeier, F. Wischmeyer, E. Niemann, H. Moller, M. Eickhoff, and G. Krotz, Mater. Sci. Eng. B 61-62, 576 (1999).

${ }^{12}$ G. H. Kroetz, M. H. Eickhoff, and H. Moeller, Sens. Actuators A 74, 182 (1999).

${ }^{13}$ C. H. Wu, C. A. Zorman, and M. Mehregany, IEEE Sensors. J. 6(2), 316 (2006).

${ }^{14}$ Homma T., Kamimura K., Cai H. Y, and Onuma Y., Sens. Actuators A 40(2), 93 (1994).

${ }^{15}$ T. Akiyama, D. Briand, and N. F. Rooij, J. Micromech. Microeng. 22, 085034, 2012.

${ }^{16}$ J. S. Shor, L. Bemis, and A. D. Kurtz, IEEE Trans. Electron Devices. 41(5), 661 (1994)

${ }^{17}$ R. S. Okojie, A. A. Ned, A. D. Kurtz, and W. N. Carr, IEEE Trans. Electron Devices 45(4), 785 (1998).

${ }^{18}$ L. Wang, S. Dimitrijev, J. S. Han, P. Tanner, A. Iacopi, and L. Hold, J. Cryst. Growth. 329, 67 (2011).

${ }^{19}$ L. Wang, S. Dimitrijev, G. Walker, J. S. Han, A. Iacopi, P. Tanner, L. Hold, Y. Zhao, and F. Iacopi, Mater. Sci. Forum. 740742, 279-282 (2013).

${ }^{20}$ X. Gao, W. H. Shih, and W. Y. Shih, Smart Mater. Struct. 18, 125018 (2009).

${ }^{21}$ X. Li, W. Y. Shih, I. A. Aksay, and W. H. Shih, J. Am. Ceram. Soc. 82(7), 1733 (1999).

${ }^{22}$ F. Iacopi, G. Walker, L. Wang, L. Malesys, S. Ma, B. V. Cunning, and A. Iacopi, Appl. Phys. Lett. 102, 011908 (2013).

${ }^{23}$ See supplemental material for the estimation of the different between the simulation and the actual results of the strain in $\mathrm{SiC}$ resistor.

${ }^{24}$ Y. Kanda, Sens. Actuators A 28, 83 (1991).

${ }^{25}$ Y. Sun, S. E. Thompson, and T. Nishida, "Strain Effect in Semiconductor: Theory and Device Applications", 1st ed., Springer (2009). 